\title{
Nietzsche: enfermedad-escritura. Hacia una terapéutica del futuro
}

\author{
Víctor Berríos Guajardo \\ Universidad Metropolitana de Ciencias de la Educación \\ (Santiago, Chile) \\ Universidad Complutense de Madrid (Madrid, España) \\ vicberrios@gmail.com
}

\section{El silencio ante Zaratustra}

En el año 1885, Nietzsche vivía, como a lo largo de toda su vida, otra de sus tantas crisis de salud. Sin embargo, la peculiaridad de esta crisis no sólo tenía el componente de la salud (o más bien dicho, de la enfermedad) y por la cual se había transformado, hacía ya un par de años, en filósofo nómada o errante en busca de mejores climas, sino que también era una crisis respecto a su obra filosófica ya escrita. Esta crisis era el resultado de una fría recepción de su obra más querida: Así habló Zaratustra. Es esta incomprensión lo que lo llevará a evaluar la totalidad de su obra escrita hasta ese momento, precisamente por el silencio del público. Un silencio doloroso ante aquella obra que Nietzsche siempre considerara como fundamental para su pensamiento, tanto en su valor estilístico y retórico, como en su 〈contenido〉. Por ello, Nietzsche manifiesta cierto <agotamiento〉 respecto del proyecto editorial del Zaratustra. Un agotamiento que no se refiere a un 
cansancio ni abandono de las tesis de Zaratustra, sino más bien remite al cansancio que provoca el no tener los lectores adecuados y, por lo tanto, la falta de <discípulos> de la filosofía nietzscheana, que en este período encarna la figura, el personaje de Zaratustra.

Es por esta razón que Nietzsche cree necesario publicar segundas ediciones de sus libros previos a Así habló Zaratustra, para así presentar su obra como unidad, no como un pensar sistemático, sino como un pensar conectado, donde Nietzsche mismo se percata que lo que ha escrito antes tiene que ver con lo que ahora es su pensamiento más maduro, más elaborado. Así habló Zaratustra debe ser puesto en contacto con sus anteriores obras, para luego dar paso rápidamente a su filosofía más acuciante, aquello que le apremia de un modo agobiante y que se transforma en ese momento en su proyecto filosófico que le ocupará por algún tiempo: la transvaloración de todos los valores. Para dichas reediciones prepara prólogos que presentan y contextualizan la obra. Con esos prólogos a las nuevas ediciones, Nietzsche quiere darle alas a sus libros para que sean leídos con interés y así, de paso, su Zaratustra sea comprendido. Precisamente aquí se nos abre un problema filosófico interesante: estos prólogos se transformarán, ellos mismos, en escritura filosófica fundamental, en la medida que ellos hablan o relatan a Nietzsche con relación a su enfermedad y su escritura. Dan cuenta de la enfermedad como escenografía de sus pensamientos y libros y, al mismo tiempo, son el relato de la superación de esa enfermedad, en la medida que construye un personaje, un filósofo llamado Nietzsche. Es finalmente la cuestión de la enfermedad-escritura y cómo superar la enfermedad en cuanto estilo de sí, o el sí mismo como obra de arte. 


\section{Enfermedad-escritura. Los prólogos como bisagra en el pensamiento-escritura nietzscheano}

Hacia 1886 nos parece que emerge un Nietzsche más sugerente, un Nietzsche donde los prólogos para las segundas o terceras ediciones inaugurarán también una etapa del pensar filosófico de Nietzsche, que muchos consideran el más fecundo y ‘filosófico〉 del pensador alemán ${ }^{1}$. Esta etapa, que incluiría también el Ecce homo como el gran prólogo (y epílogo) de su vida, son fundamentales en cuanto a ideas, experiencias de vida y estilo. Por aquel tiempo, cuestión que nunca abandonará, viaja por Europa buscando un buen clima, una alimentación adecuada, un lugar que le permita cierta tranquilidad para pensar y trabajar, pues convive con la soledad, sin lazos de amistad. Nietzsche es una sombra y un fantasma que recorre Europa, Nietzsche es su propia sombra. Por lo mismo, le parece muy importante revisar su vida, su pasado y su pensamiento ya publicado. Considera necesario reinscribirse y reescribirse, en noviembre de 1886, y entiende su labor de un determinado modo:

1 No analizaremos con detención las «divisiones〉 en períodos que se han hecho de la obra de Nietzsche; sin embargo, a modo de síntesis muy general y breve, podemos decir que la mayoría de las hipótesis que desean organizar temáticamente la obra de Nietzsche, reconocen entre 3 o 4 períodos, según sea el 〈lugar〉 que se le entregue a Así habló Zaratustra: a) el joven Nietzsche hasta las 4 intempestivas; b) el Nietzsche <ilustrado> desde Humano, demasiado humano hasta La ciencia jovial; c) La obra poética Así habló Zaratustra y d) desde Más allá del bien y del mal hasta Ecce homo y el fin de la vida lúcida de Nietzsche. Por ahora, nosotros solamente estableceremos que a partir del año 1886 se opera, a partir de los prólogos, un giro y una intensidad en la temática y el ejercicio escritural de Nietzsche que remite, en primer término, al proyecto de la transvaloración de todos los valores y la crítica al cristianismo, y que finalmente concluirá en Ecce homo como intento por establecer una terapéutica del futuro, como invención de sí. 
Por lo demás, no ha ocurrido nada, exceptuando una tormenta marina en gran estilo, y mucha enfermedad y melancolía por mi parte, esto último en muy pequeño estilo: que para algo así es el peor estilo. Había aún muchas cosas que disponer y pensar para hacer que la nueva edición de mis escritos por parte de Fritzsch fuera lo más ventajosa posible para el editor. Ahora los escritos anteriores (hasta Aurora) están listos para distribuir y ya distribuidos, con bonitos vestiditos nuevos y provistos por mí de prólogos largos y poderosos. Ayer ya he dejado listos para imprimir los prólogos de Aurora y La gaya ciencia; el final de La gaya ciencia será un apéndice con el título «Canciones del Príncipe Vogelfrei». -Estos 5 prólogos quizás sean la mejor prosa que he escrito hasta ahora $[\ldots]^{2}$.

Nietzsche permanentemente comprende enlazados escritura, estilo y vida. Es en este sentido que estos prólogos, esa mejor prosa escrita hasta entonces, según Nietzsche, lo exponen intentando dar unidad o desarrollo continuo a su filosofía, preparar oídos y ojos para el futuro y, de algún modo, cerrar heridas con el pasado. Cree necesario reinscribir sus anteriores obras en una suerte de proyecto, bajo el cual comprende toda su filosofía, su trabajo filosófico. Quiere lograr una visión más cohesionada de su pensamiento, en la medida que tras el Zaratustra, que ha recibido un frío silencio, considera necesaria una preparación para los lectores futuros. Por ello, estos prólogos tienen un doble movimiento: por una parte,

2 KSB 7, S. 281. Nietzsche, F. (2011: 241). Los prólogos a los que Nietzsche hace referencia están fechados hacia el año 1886: El nacimiento de la tragedia (SilsMaría, Alto Engandina, agosto de 1886); Humano, demasiado humano I (Niza, primavera 1886); El viajero y su sombra (Humano, demasiado humano II) (SilsMaría, Alto Engandina, septiembre 1886); Aurora (ruta hacia Génova, otoño 1886); y finalmente La ciencia jovial (En ruta hacia Génova, otoño 1886). 
presentan estas obras anteriores, ponen una mirada en unos textos pasados, intentando dar cuenta de cómo surgieron, bajo qué circunstancias; $y$, al mismo tiempo, como segundo aspecto tienen estos prólogos mucho que ver con lo que Nietzsche está pensando como problemática filosófica en ese momento y que es, en términos muy generales, preparar el gran asalto a occidente, a su moral y su filosofía:

[...] había buenas razones para que entonces, cuando surgieron esas obras, me impusiera silencio -estaba aún demasiado cerca, demasiado «adentro» y apenas si sabía lo que había ocurrido conmigo [...] Mis escritos presentan un desarrollo continuo, que no será sólo mi vivencia y mi destino personal -sólo soy el primero, una generación emergente comprenderá por sí misma lo que yo he vivido y tendrá un fino paladar para mis libros. Los prólogos podrían poner de manifiesto lo que hay de necesario en el curso de ese desarrollo: lo que de paso tendría la utilidad de que quien ha hincado el diente en uno de mis escritos, tendrá que vérselas con todos ${ }^{3}$.

La escritura nietzscheana se comprende no sólo como ejercicio para sí mismo, también se escribe para otro u otros, que posiblemente aún no habiten la tierra. Esto es lo que se ha dado en llamar una escritura y pensamiento intempestivo, y es de suma importancia, pues lo que venimos a decir aquí es que Nietzsche escribe para un futuro, es el primero de una generación por venir; pero, al mismo tiempo, escribe sobre un pasado (sus antiguas obras) sin dejar de preocuparse por su presente. Por ello, los prólogos son un gozne, una bisagra en su obra; es decir, en los prólogos lo que se expondría es la

$3 \quad$ KSB, 7, S. 225. Nietzsche, F. (2011: 199). 
íntima relación entre pensamiento y vida y es ahí donde, a nuestro juicio, se presenta un aspecto interesante para comprender cómo la filosofía se interpreta a sí misma y en qué medida esa interpretación supone determinados modos de relación con el mundo, y cómo el pensar también es el resultado de ciertas interpretaciones que son también valoraciones del mundo. Nietzsche con esto desmonta una "verdad" de la filosofía tradicional: afirma que la filosofía no se relaciona con el mundo valorándolo o interpretándolo tal cual es éste desde una racionalidad objetiva, sino que, por el contrario, la valoración o interpretación que hacemos del mundo es el resultado de la valoración o interpretación de un determinado organismo, de un determinado ser fisiológico. Estos prólogos vendrían a ser el inicio -o al menos la primera manifestaciónde esto que será un tema fundamental en el último Nietzsche: la relación entre fisiología y filosofía y, en sentido más amplio, la relación entre filosofía y terapéutica. Podemos plantear entonces que, para Nietzsche, en los prólogos se juega un modo de comprender el ejercicio filosófico, esto es, cómo la filosofía se preocupa del sí mismo, de la construcción de una subjetividad que comprenda dentro de ella la importancia de aspectos fisiológicos, dietéticos, climáticos, enfermedad, decadencia, cuerpo, y que conformarán un estilo de escritura que, finalmente, será un estilo de vida, pues escritura y vida están relacionadas. Así, el prólogo en Nietzsche tiene una característica muy especial, pues presenta su obra, en este caso una obra anterior y la contextualiza en la propia vida, pero, al mismo tiempo, comprendiendo que esa obra también habla de algo distinto y más profundamente que del propio "yo". La prosa de los prólogos es la mejor prosa porque habla de un 〈yo〉 (Nietzsche), pero constituyéndose desde una determinada instancia conflictiva con lo ya sido y con lo que se es, 
precisamente para superarse y, al mismo tiempo, explica cómo se ha constituido esa obra, ese personaje, esa vida. Entonces, podemos decir que el ejercicio del prólogo es el ejercicio de un Nietzsche expuesto con su obra, confrontada a ella, contextualizándose, lo que al mismo tiempo es un modo de comprender su filosofía y a sí mismo.

¿Qué nos anuncian y enuncian esos prólogos? ¿Qué ideas expresan sobre Nietzsche y su filosofía? ¿Cómo leer dichos prólogos? Obviamente son muchas las posibilidades para leer estos textos. Aquí rastrearemos una, aquella que nos parece que muestra cómo Nietzsche comprende su filosofar y, al mismo tiempo, configura una noción de filosofía que marcará el desarrollo de su pensamiento posterior, pues es en los prólogos donde Nietzsche expondría la clave problemática que permitiría interpretar la escritura y filosofía nietzscheana. Los escritos de Nietzsche son su propia vida, escritos a pesar de ella misma. La expresión a pesar de (trotz) concentra gran parte de cómo Nietzsche entiende su obra y su producción filosófica y de hecho es citada muchas veces tanto en libros como en cartas. Con dicha expresión, podemos comprender el origen de toda la producción de Nietzsche, pues ésta se debe entender como aquel triunfo sobre sí mismo entendido como superación. Diríamos genéricamente: Nietzsche produce su filosofía afirmativa, a pesar de su enfermedad, de su organismo debilitado. Por ello, el a pesar de es una suerte de lema o motto, que comprende el ejercicio nietzscheano ${ }^{4}$. Así,

4 Si se revisa la biografía de Nietzsche, se verá claramente que toda su vida a partir 1869 (dato no menor en una posible lectura psicológica o incluso psicoanalítica de su vida), año en que accede a la cátedra de filología clásica en Basilea, está llena de eventos y referencias a enfermedades y dolores que jamás serán superados. Ahora bien, lo interesante es que en estos prólogos, Nietzsche presenta su filosofía precisamente como un ejercicio que surge a 
Nietzsche quiere pensar juntos y unidos, precisamente aquello que jamás se piensa unido: vida, filosofía y escritura. Esta expresión, a pesar de, a parentemente menor o anecdótica, capta, liga, anuda un problema complejo, el problema de la vida. El a pesar de no es la afirmación dialéctica a la resolución de la vida ni a la explicación de por qué se crean obras, de por qué se filosofa. Afirmar no es triunfar, no es ganar, es querer. Por ello, Nietzsche pretende mostrar con este a pesar de que los resultados de una vida no dicen relación con una comprensión ni optimista, ni monolítica de ella, sino que cada vida es el resultado de fuerzas que se contraponen, que se enfrentan, modelando así, por la vía del ensayo y del error, una suerte de obra que cada vida es. Cada vida es lo que se cuenta de ella, lo que cada uno cuenta de ella y le da forma. La vida es estilo. Por eso, la escritura es una instancia de la vida, o puede ser considerada en cierto sentido o de algún modo, la vida misma, pues la vida es tal como se la relata cada uno a sí mismo. Por eso hablamos de enfermedad-escritura, pues no son dos actividades que sólo se complementarían en Nietzsche, sino más bien, se escribe y se vive al mismo tiempo; Nietzsche escribe-vive, en la medida que la enfermedad produce escritura. Enfermedad-escritura es el pensar de Nietzsche, y Ecce homo será la superación (no en sentido dialéctico, sino

pesar de esta inevitable condición, o dicho de otro modo, la enfermedad como condición del pensar, precisamente en cuanto posibilita su superación. En este sentido, Nietzsche piensa la enfermedad como determinante del pensar, pero en cuanto a que ella nos impele a pensar, pues posibilita su propia superación, donde lo sano comprende, en su interior y en su propio concepto, a la enfermedad y no como su negación o anulación, como sería el caso de nuestras sociedades, donde lo enfermo, como también por ejemplo la muerte, son negadas, anuladas y ocultadas, en referencia a un cuerpo supuestamente «sano». Sólo mencionemos que en el neoliberalismo se propugna un cuerpo capaz de competir y auto producirse para así ganarse la vida. 
creativo, narrativo diríamos aquí) de la enfermedad, y de paso será entonces la invención de la propia vida. "Cómo se llega a ser el que se es», el subtítulo de Ecce homo significaría entonces, «cómo me relato mi vida a mí mismo, cómo me invento a mi mismo como personaje» es decir, «soy el resultado de mi propia escritura». Así, finalmente dicha obra (Ecce homo), que para nosotros viene a ser la obra fundamental de Nietzsche, en cuanto ejercicio retórico y pletórico de sí, será manifestación de una retórica del cuerpo, no sólo en cuanto su filosofía pone de manifiesto el cuerpo como aspecto que ha sido olvidado y negado en la historia de la filosofía, sino que, más específicamente, Nietzsche escribe y piensa con el cuerpo, en la medida que toda su retórica, todo su discurso, establecerá la inclusión del cuerpo en su filosofar. Por esto, su retórica en primera persona o lo que para algunos será manifestación de su megalomanía y locura, serán más bien el intento de establecer un lenguaje, una escritura que incluya como problemas filosóficos los problemas del cuerpo, la dieta, el clima, el sistema nervioso, la enfermedad, etc. Por esto, su escritura, su filosofía, será una terapéutica filosófica ${ }^{5}$, por-

5 Entendemos esta expresión «terapéutica filosófica〉 como el ejercicio filosófico realizado principalmente por pensadores griegos y latinos que comprenden el filosofar y la filosofía como un ejercicio de cuidado del alma, cuerpo, una dietética del cuerpo y del alma. Serán, a nuestro entender, Nietzsche y Foucault, quienes «recuperan〉 este sentido originario del pensamiento filosófico, claro está, con sus propias peculiaridades. En el caso de Nietzsche, nos parece precisamente que su terapéutica no consiste en «sanarse` $\mathrm{o}$ 〈mejorarse» sino en «superarse> lo que significa asumir la enfermedad (y el nihilismo) como aspecto de la fortaleza y la salud. En este sentido, la cuestión de la terapéutica deberá ser comprendida como el «arte de curarse», el arte de darse la salud, por lo que terapéutica no debe ser comprendida necesariamente como un otro que (me cura), sino el ejercicio consigo mismo, la relación consigo mismo, que en este caso es escritural y, por lo tanto, filosófica. Los prólogos y el Ecce homo serán precisamente los documentos, la escritura (ella misma, terapéutica) los que la expondrían. Respecto a Foucault, toda la llamada últi- 
que mediante ella supera la enfermedad, en la medida que se inventa a sí mismo, inventa una vida, la relata.

Ecce homo y la retórica del cuerpo.

Hacia una terapéutica del futuro

Ha sido Ecce homo el libro de Nietzsche al que menos estudios se le han dedicado. En general, se le entiende como autobiografía, pero una muy peculiar, pues para muchos presenta rasgos delirantes de megalomanía y abundancia de datos falsos. Por ello, no se le ha dado suficiente atención; por el contrario, ha sido desacreditado, ya sea por su cercanía cronológica con su locura (que será una evidencia post escritural), por la autoreferencia excesiva (por ejemplo, su dudosa genealogía familiar), o por su megalomanía (una retórica excesiva). Esto ha ocultado y negado el aporte que tiene este libro para la comprensión del pensamiento de su autor. Nos parece que, por el contrario, es un gran texto. Ecce homo como texto, con-textualiza un modo de pensar, en donde el mismo pensar se disloca, pierde su lugar tradicional para ubicarse en otro lugar. Ese otro lugar, condición de su constituirse en texto, no es otro que entender la filosofía como experimento, como ejercicio vital, como ejercicio de escritura y estilo. Y si asumimos como lema aquella frase «¿Cómo no había de estar agradecido a mi vida entera? Y así me cuento mi vida a mí mismo» ${ }^{6}$, tenemos que Ecce homo constituye finalmente

ma etapa de su pensamiento, inaugurada por el curso «La hermenéutica del sujeto» (1982), hasta el último curso «El coraje de la verdad» (1984), pasando por los tres volúmenes de la Historia de la sexualidad, nos parece que pueden ser considerados como parte de una comprensión de la filosofía como terapéutica o, en palabras de Foucault, como «cuidado de sí̀. 
el texto-Nietzsche y a Nietzsche como texto, porque lo que tenemos entre manos, ojos, oídos y olfato es un relato que más que contar lo que ha sido la vida de Nietzsche, es contársela a sí mismo, como triunfo y superación de ella misma. Con ello, se constituye el personaje-Nietzsche, en una puesta en escena, por parte de otro que se quiere apropiar de ese sí mismo, después de una larga batalla con su enfermedad, con su herencia, con su procedencia. La fuerza textual de un libro como éste, es relatar una historia (hacia atrás), pero para mostrar que se deja de serlo, constituyéndose hacia un futuro por-venir, en un afán por dejar de ser lo que se fue, incorporándolo, del mismo modo como lo sano incorpora a la enfermedad o el cuerpo incorpora los alimentos, para constituirse en lo que se es, para constituirse como pensador del futuro, en aquel que considera dividirá la historia en dos.

Sobrepasa [Ecce homo] de tal manera el concepto «literatura», que propiamente incluso en la naturaleza no existe una analogía comparable: hace estallar, literalmente, la historia de la humanidad en dos trozos-supremo superlativo de dinamita $[\ldots]^{7}$.

Ecce homo sobrepasa el concepto de literatura, en la medida que no responde como texto a un género literario; sin embargo, sí es literatura en la medida que elabora una narración de su vida, una narración que quiere dejar de manifiesto que él es ese relato, ese triunfo de cómo llegar a ser el que se es. Toda vida, ya no sólo la de Nietzsche, es el resultado de ese relato, de esa narración que nos hacemos sobre nosotros mismos, ése es el estilo entendido como modo de vida, como forma de vida. Por tanto,

$7 \quad$ KSB 8, S.513. Nietzsche, F. (2012: 323). Los corchetes son míos. 
Ecce homo será como obra o libro, una suerte de Summa, pero no de saberes filosóficos ni disciplinares, será una Summa de lo que es cada vida, en este caso la suya particular, que quiere presentarse como modélica no en cuanto una vida a imitar, sino modélica en el proceso de conocerse a sí mismo, en el proceso de inventarse a sí mismo. Es un texto que constituye la puesta en escena de toda la filosofía de Nietzsche y, en el cual, se juega todo Nietzsche. Por eso es el texto-Nietzsche. Quizás por ello el uso de la expresión «Ecce homo», «he aquí el hombre», en la medida que invierte el sentido cristiano, para convertirse en el lema del anticristo, el anti-modelo cristiano, pero ahora, no en la medida de una crítica despiadada a la moral cristiana (labor realizada más precisamente en El anticristo, obra que será en definitiva el libro de la «Transvaloración de los valores»), sino más bien dando vueltas, invirtiendo, transvalorando ese sentido del «Ecce homo» cristiano, más sufriente, más doliente. Nietzsche se presenta escrituralmente a sí mismo ante el público, no como doliente, sino como aquel que se ha superado, en la medida que se ha conocido, en la medida que se ha recetado a sí mismo, las dosis necesarias de salud, de libros, de alimentos, de climas. Ha llegado a ser el que es, en la medida que ha conocido su propio cuerpo, su propio organismo, ha sido su propio médico: Terapéutica del futuro. Nietzsche quiere crear lectores del futuro y una terapéutica del futuro será, precisamente, rescatar un sentido de la filosofía griega y romana, que es entender la filosofía como medicina y el filósofo como médico. Filosofar es ser su propio médico, es recetarse las dietas bibliográficas, alimenticias, climáticas, de afectos y amistad, necesarias para cada vida.

La constitución como personaje que desarrolla Nietzsche en el Ecce homo tiene como elemento fundamental el elaborarse como relato, como estilo, como obra. Aquel inicio desbordante, 
ese doble origen (aristocrático y decadente) gradualmente va desapareciendo para establecer una nueva filiación, una filiación que lo ligue a unos personajes que le den grandeza al identificarse con ellos. "Yo, como mi padre, ya he muerto, y como mi madre vivo todavía y voy haciéndome viejo" ${ }^{\text {; }}$ supone que en ese punto, a la mitad de la vida, en media vita, esa doble naturaleza debe ser superada. Y la única posibilidad de hacerlo es incluirse en una constelación de nombres, de personajes. Es necesario dar testimonio de la propia vida, de cómo esa vida es el monumento a una crisis y su superación. La negación de su filiación sanguínea debe ser entendida precisamente en este sentido, como el desbordante triunfo, frente a la fatalidad asociada a su herencia:

La continuidad fisiológica hace posible tal disharmonia praestabilita [desarmonía preestablecida] [...] Con quien menos se está emparentado es con los propios padres: estar emparentados con ellos constituiría el signo extremo de la vulgaridad. Las naturalezas superiores tienen su origen en algo infinitamente anterior, y para llegar a ellas ha sido necesario estar reuniendo, ahorrando, acumulando durante larguísimo tiempo. Los grandes individuos son los más antiguos: yo no lo entiendo, pero Julio César podría ser mi padre -o Alejandro, ese Dioniso de carne y hueso[...] En el instante que escribo esto, el correo trae una cabeza de Dioniso[... $]^{9}$.

Así, lo más cercano es lo más lejano y viceversa. La identificación con Julio César o Alejandro Magno se enmarca en el gesto retórico de inaugurar una voz privilegiada, una voz superior que habla desde el triunfo. Eleva, por ello, un acta

8 EH. KSA 6, S.264. Nietzsche, F. (1976: 21).

9 EH. KSA 6, S. 268. Nietzsche, F. (1976: 25-26). 
de nacimiento, de segundo nacimiento. Nietzsche, por lo tanto, lo que intenta es presentarse desde un lugar que ya no es el lugar natural al que todos recurrimos: nuestros padres, nuestra sangre, nuestra herencia. Nietzsche pretende filiarse, reconocer su acta de nacimiento en otro lugar, remitir a otro que ya no son sus padres. Su sabiduría es reconocible sólo en esos personajes, en ese dios que es Dioniso. Su herencia debe ser borrada, para mostrar su superación del doble juego aristocrático-decadent. $\mathrm{Y}$ es precisamente la imagen de su padre la que le acompaña problemáticamente, la que debe desaparecer, la que debe asesinar. Nietzsche quiere vengar la muerte de su padre, vengarla para, al mismo tiempo, redimirse y liberarse de su herencia, aquella herencia fatal que le indicaba que moriría a los 36 años. Nietzsche no murió a esa edad y con ello mata esa sombra, a su padre que es una sombra, que arrastra su condición, la muerte prematura. Nietzsche, en el Ecce homo, mata a su padre, lo que hay de muerto en él, lo que hay de sombra en él, precisamente porque así da nacimiento a lo que perdurará. Así como en Hamlet, cuando el espectro de su padre habla con él, comienza la tragedia, pero también la comedia (su actuación, su personificación, su locura, su bufonería). Nietzsche ha vivido una vida demasiado ligada a ese pasado, a esa herencia enfermiza y Ecce homo es el acta de nacimiento del filósofo Nietzsche, donde su rúbrica cambia, su firma es otra, ya no es la rúbrica Nietzsche, sino Dioniso: «¿Se me ha comprendido? -Dionisos contra el Crucificado» ${ }^{10}$, una rúbrica que pretende ser un destino, es decir, se crea para un futuro.

10 EH. KSA 6, S.374. Nietzsche, F. (1976: 132). 
La posibilidad de superación, que en Nietzsche será desaprendizaje o cambiar lo aprendido ${ }^{11}$, la posibilidad de abandonar lo que se era para constituirse en otro que soy yo mismo, constitución realizada como relato de lo que se es, es posible gracias a un saber abismal, la verdad. El Ecce homo como relato, como documento, como artificio que constituye a Nietzsche como personaje, es posible gracias a que se ha sido capaz de soportar la verdad, como Hamlet:

No conozco lectura más desgarradora que Shakespeare: ¡cuánto tiene que haber sufrido un hombre para necesitar hasta tal grado ser un bufón!- ¿Se comprende el Hamlet? No la duda, la certeza es lo que lo vuelve loco[...] pero para sentir así es necesario ser profundo, ser abismo, ser filósofo[...] Todos nosotros tenemos miedo de la verdad ${ }^{12}$.

11 Desaprendizaje o cambiar lo aprendido. Toda la filosofía de Nietzsche puede ser comprendida bajo esta expresión. Incluso la Transvaloración de todos los valores es un cierto desaprender, habitar de otro modo las costumbres y la moral. Ecce homo será precisamente el ejercicio mayor de desaprendizaje en la medida que expone un registro de autoconocimiento que tiene que ver no con la introspección o el autoconocimiento del yo íntimo, sino un cuerpo y su cuidado, lo que va a implicar, al mismo tiempo, el conocimiento de sí, en la medida que se auto constituye. «-Se me preguntará cuál es la auténtica razón de que yo haya contado todas estas cosas pequeñas y, según el juicio tradicional, indiferentes; al hacerlo me perjudico a mí mismo, tanto más si estoy destinado a representar grandes tareas. Respuestas: estas cosas pequeñas -alimentación, lugar, clima, recreación, toda la casuística del egoísmo-, son inconcebiblemente más importantes que todo lo que hasta ahora se ha considerado importante. Justo aquí es preciso comenzar a cambiar lo aprendido». EH. KSA, S. 293. Nietzsche, F. (1976: 52-53). Por eso en definitiva, en Ecce homo lo que hay es una retórica del cuerpo, en la medida que la enseñanza terapéutica será cambiar desde dónde hemos aprendido y cómo lo hemos hecho. Pensar es, entonces, pensar con el cuerpo. Lo importante no es que exista una tematización filosófica del cuerpo en Nietzsche, sino más bien, lo que hay es pensar con el cuerpo. 
La locura de Hamlet y la de Nietzsche es retórica, trágica y bufonesca. Como Hamlet, el precio de la verdad será hacer un papel, teatralizar(se). De algún modo, la locura (que en Nietzsche será esa retórica hiperbólica y megalómana) oculta la verdad y su desesperación. La duda no enloquece a Descartes, guía su búsqueda, racionaliza su necesidad; la certeza sí enloquece a Nietzsche y a Hamlet. Los enloquece y los transforma en bufones, en irónicos, en desmesurados para soportar esa verdad.

En este punto no se puede eludir ya el dar la auténtica respuesta a la pregunta de cómo se llega a ser el que se es. Y con ello rozo la obra maestra en el arte de la autoconservación, -del egoísmo[...] Suponiendo, en efecto, que la tarea, la destinación, el destino de la tarea superen en mucho la medida ordinaria, ningún peligro sería mayor que el de enfrentarse cara a cara con esa tarea. El llegar a ser lo que se es presupone no barruntar ni de lejos lo que se es. Desde este punto de vista tienen su sentido y valor propios incluso los desaciertos de la vida, los momentáneos caminos secundarios y errados, los retrasos, las «modestias», la seriedad dilapidada en tareas situadas más allá de la tarea (Nietzsche, 1976: 50-51).

¿Cómo llegar a ser el que se es? ¿Cómo constituirse efectivamente como personaje? ¿Cómo constituir un relato? ¿Cómo constituirse en un relato? No teniendo ni la más remota idea de qué sea nuestra tarea, ni proponérnosla, ni elaborarla. Se es destino cuando dicha tarea nos asalta, y cada uno es un destino. Llegar a ser el que se es no es encontrar una identidad, una verdad que está ya ahí para ser descubierta. La tarea, el destino, no suponen para nada que sepamos de antemano esa tarea, sino que la tenemos que elaborar, narrar, en la medida que esta vida es una vida de desaciertos, de fracasos, de caminos errados. ¿Será ésa la verdad abismal que debemos 
soportar? ¿Será descubrir que la vida es un cúmulo de errores, de borradores de texto, de ensayos que siempre fracasarán? ¿No somos cada uno de nosotros el relato que nos hacemos para soportar esa verdad? Entonces, ¿será la locura de Nietzsche el resultado y la estrategia para soportar esa verdad?

Bibliografía

Nietzsche, F. (2012). Correspondencia, Volumen VI, J. B. Llinares (tr.). Madrid: Trotta.

Nietzsche, F. (2011). Correspondencia, Volumen V, J. L. Vermal (tr.). Madrid: Trotta.

Nietzsche, F. (1988). Sämtliche Werke. Kritische Studienausgabe in 15 Bänden (KSA). München: dtv de Gruyter.

Nietzsche, F. (1986). Sämtliche Briefe. Kritische Studienausgabe in 8 Bänden (KSB). München: dtv de Gruyter.

Nietzsche, F. (1976). Ecce homo, A. Sánchez Pascual (tr.). Madrid: Alianza Editorial. 
Resumen

En 1885, Nietzsche decide volver a publicar sus antiguos libros para los cuales escribirá prólogos. En ellos, desarrollará un relato de sí mismo, lo que significa que se inventará a sí mismo a través de la escritura. Esta relación entre escritura y enfermedad tendrá su mayor desarrollo en Ecce homo, donde adquiere un carácter terapéutico, precisamente en la búsqueda del estilo, como invención retórica de sí, mediante la cual Nietzsche se crea a sí mismo como filósofo. Así, temas como la dietética, la falsa genealogía o la identificación con personajes históricos no serán la retórica de un loco, sino expresión de una retórica del cuerpo.

Palabras clave: enfermedad, escritura, terapéutica, retórica del cuerpo, Ecce homo.

\section{Summary}

In 1885, Nietzsche decided to republish his old books for which he wrote prologues. In them, he developed an account of Nietzsche himself, what it means to be invented himself through writing. This relationship between writing and disease had its greatest development in Ecce homo, which takes on a therapeutic basis, precisely in search of style and rhetoric of self invention, in which Nietzsche creates himself as a philosopher. Thus, issues such as diet, false genealogy or identification with historical figures will not be the rhetoric of a madman, but expression of the body's rethoric.

Keywords: disease, writing, therapeutic, body's rethoric, Ecce homo. 